Article

\title{
The Challenge of Producing and Marketing Colloidal Silver Water Filters in Nepal
}

\author{
Anne Bogler and Regula Meierhofer * \\ Department of Water and Sanitation in Developing Countries (Sandec), Swiss Federal Institute of \\ Aquatic Science and Technology (Eawag), Ueberlandstrasse, 133, Dübendorf 8600, Zürich, \\ Switzerland; E-Mail: anne_musik@web.de \\ * Author to whom correspondence should be addressed; E-Mail: regula.meierhofer@eawag.ch; \\ Tel.: +41-058-765-5073.
}

Academic Editor: Miklas Scholz

Received: 21 May 2015 / Accepted: 1 July 2015 / Published: 7 July 2015

\begin{abstract}
Background: Obtaining safe drinking water can be a challenge in Nepal. By training potters and setting up production sites for Colloidal Silver Filters, several non-governmental organizations have tried to provide local people with a low-cost option for household water treatment. Out of 19 trained entrepreneurs, only four are currently producing filters. The goal of this evaluation was to find out what conditions lead to the successful continuation of the production and the reasons for failure. Methods: The evaluation of the potters was based on a Qualitative Comparative Analysis and the conditions looked at were: "Production", "Collaboration", "Market" and "Potter". Results: Analysis showed that production problems and insufficient demand led to the termination of ceramic filter production and that both trouble-free production and high demand are necessary for a sustainable business.
\end{abstract}

Keywords: household water treatment; ceramic filters; safe drinking water; developing countries; marketing water treatment products; qualitative comparative analysis

\section{Introduction}

More than 700 million people do not have access to an improved source for drinking water and an estimated 1.8 billion people do not consume safe drinking water [1]. Household water treatment, if 
applied correctly and consistently, is a strategy to reduce the health risks related to the consumption of unsafe drinking water [2]. Different methods for water treatment at the household level have been promoted to improve drinking water quality. A trial conducted in Nepal with different methods for water treatment, such as solar water disinfection, chlorination, boiling and ceramic filters, revealed that, without considering the purchase costs, the most popular method across all test sites was the ceramic filter, due to its ease of use [3].

Treating drinking water through the use of ceramic filters, however, can only be taken up and sustained if people have reliable access to these products [4]. Therefore, different organizations have worked to establish ceramic filter production sites in Nepal in order to give local communities better access to water treatment products at the household level.

\section{Ceramic Filters in General and in Nepal}

Clay is a material used in many different cultures all over the world [5-7] and is often used to produce water storage vessels [8]. As identified by Oyanedel-Craver and Smith (2008), a variety of ceramic water filters has been developed as a "Point of Use Treatment" option for drinking water in developing countries [9].

The Guatemalan Chemist Fernando Mazarieges invented a pot-shaped silver-impregnated ceramic filter, which is one of the most widely used designs for ceramic water filters. The potter and sociologist Ron Rivera met Mazarieges in Central America after the destruction wrought there by Hurricane Mitch in 1998. He picked up the idea of making this kind of filter and set up local workshops in different countries together with the non-governmental organization Potters for Peace $[10,11]$. The goal was to use locally available material and train local people to produce this low-cost option for drinking water treatment [9]. Now, there are more than 30 factories producing such filters, for example, in Ghana, Yemen, Cambodia, Guatemala, Kenya, and Indonesia, as well as other countries of the developing world. The number of production sites worldwide continues to expand [10].

The pot-shaped silver-impregnated ceramic filter of Potters for Peace is made of clay and a burnable material that leaves behind pores when the filter is fired, providing the first elimination mechanism for microorganisms. The second disinfection process is the impregnation of the filter with colloidal silver, which increases the percentage of pathogens eliminated and prevents the formation of a biofilm within the filter [8]. The pot-shaped filter can be placed in varying types of receptacles, made from different kinds of materials, which are covered with a lid. Water is poured into the upper part of the filter and consumers just have to wait for the water to trickle through the porous ceramic before they can withdraw safe drinking water, using a tap at the bottom edge of the receptacle [8,9]. A schematic and a picture of the filter are depicted in Figure 1.

The Nepali ceramic filter, which is the subject of this evaluation, has a design similar to the Potters for Peace filter. The main difference is that instead of the whole pot, only its bottom is made of porous material. The bottom is produced in a disk shape and later fixed inside the pot-shaped filter-holder, using a mixture of white cement and marble powder. The filter-holder is placed inside a ceramic receptacle with a ceramic lid [12]. The American non-governmental organization Village Forward, founded by David Elliot in 2001 as Solutions Benefitting Life Institute, developed the design of this colloidal silver filter (CS-filter) in collaboration with the Nepali potter Hari Govinda Prajapati [12]. 
The organization's mission is to relieve two burdens affecting poor people in Nepal: Poverty, by creating local employment, and water borne diseases, by providing a low-cost household water treatment and storage system (HWTS) to local people [12]. By 2014, Village Forward has trained eight potters to produce all the filter components except for the disk and has set up their production sites. The disk itself is produced only by Hari Govinda Prajapati and is distributed to the other potters.
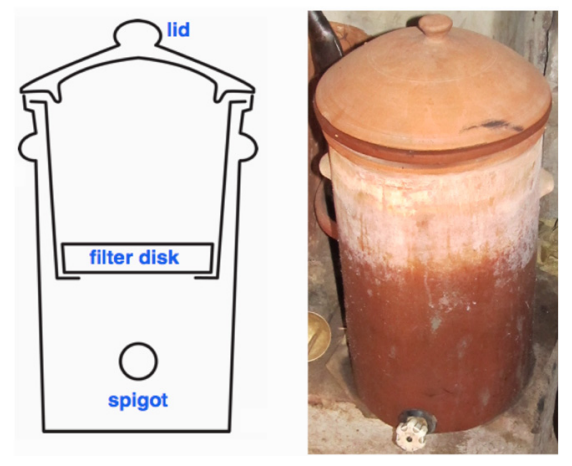

Figure 1. Schematic of the filter (adapted from [12]) and a picture of a filter used in one of the potters' households (taken by the author).

Village Forward has also worked in collaboration with different organizations to train eleven more potters, who were then supported by the respective organizations during the establishment of their production sites. However, despite the fact that 19 local entrepreneurs have been trained to establish ceramic filter production, only very few of these micro-entrepreneurs are still producing the CS-filter.

According to Anderson and Billou (2007), the marketing of health products in low income communities has been challenging due to corruption, poor infrastructure, non-existent distribution channels, illiteracy, the lack of robust and enforceable legal frameworks, and religious or racial conflict [13]. The goal of this study was to analyse the output of the efforts to establish ceramic filter productions and the marketing efforts in Nepal and, therefore, contribute to a better understanding of how to successfully promote products for drinking water treatment. One objective was to identify the conditions supporting the successful, sustainable operation of these ceramic filter businesses, as well as the reasons for failure. A project can have a long-lasting impact only when it succeeds in building up self-sustaining production. Another objective was to identify what activities could help the potters to establish, improve and sustain their production.

\section{Methods}

\subsection{Data Collection: Interviewing Potters and Organizations}

Between October and December 2014, the owners of 14 ceramic filter production sites in Nepal were visited and qualitative interviews using a structured interview guide were conducted. Nearly all sites are located in the Terai, although one is in the Hilly Region and another is in the Kathmandu Valley. Contact with the other five trained potters could not be established.

The questionnaire was developed with input from local water and sanitation experts to accommodate for cultural specificity and was structured around the business model canvas developed by Osterwalder (2007) to address the principal aspects of the entrepreneurs' business models. 
The business model canvas is a strategic management and entrepreneurial tool to describe and pivot business models. It includes the following aspects: Key partners, key activities, resources, value proposition and competition, customer relationship and marketing, cost structure and revenue [14]. The interviews were conducted by a team of a Nepalese and an international researcher. All questions were formulated in Nepalese and the answers were translated into English on site. The interviews were digitally recorded and later transcribed and translated. The interviews were also complemented with structured observations concerning the production and management of the businesses.

In addition, three qualitative interviews were conducted with the managing staff of the organizations supporting the training and establishment of the production sites: Village Forward, International Development Enterprises (IDE) Nepal and Support Activities for Poor Producers of Nepal (SAPPROS Nepal). IDE and SAPPROS Nepal worked together on the joint project called the Sanitation Marketing (SanMark) Initiative. Representatives from HELVETAS, which also collaborated with Village Forward on the establishment of production sites, could not be interviewed during the author's visit.

\subsection{Defining Conditions for Qualitative Comparative Analysis}

In most of the 19 cases, production had ceased or had never started. A Qualitative Comparative Analysis (QCA) was done to gain a more systematic understanding of the conditions that lead to the successful and sustainable operation of ceramic filter production, as well as the reasons why most of the businesses have not succeeded. QCA is a case study oriented approach that assists the researcher in the analysis of patterns in the assessed cases through the study of set-theoretic relationships between causally relevant conditions and a specified outcome [15]. The approach supports the researcher in capturing the complexity of cases. This implies that although one outcome can be produced by a combination of conditions, several different combinations of conditions may produce the same outcome or a given condition may have a different impact on the outcome [16]. QCA has also been used to support researchers in the understanding of complex cases and to deliver meaningful results, using only a small number of samples [17-19]. For example, although most applications of QCA are conducted in studies of 10 to 50 cases [16], studies based on only five [20], six [21], or seven cases [18,22,23] have been published. The results allow for a certain level of generalization but should be limited to the examined population.

The QCA method uses truth tables to find paths that lead to the determined outcome, which for this study is the continuation or termination of ceramic filter production, where a path consists of causal combinations, that show if different conditions are present or absent [19,24-26]. The conditions are defined according to the available information and a path is evaluated by its consistency and coverage [25].

Only the eight potters who had successfully started production were part of the QCA. The case of Hari Govinda Prajapati was excluded from the analysis because his situation and business is different from the others. He is their trainer and co-developer, as well as the producer of the filter disks, which is a part necessary for all of the potters' businesses.

The information gained through the specific questions was structured into eight conditions as shown in Table 1. The table also shows the weight given to each question, which is explained in more detail below. 
Table 1. Interview questions grouped into eight conditions and weighted according to their influence.

\begin{tabular}{|c|c|c|c|c|c|}
\hline \multicolumn{3}{|c|}{ External Conditions } & \multicolumn{3}{|c|}{ The Potter } \\
\hline Condition & Questions & $\mathbf{W}$ & Condition & Questions & $\mathbf{W}$ \\
\hline \multirow{5}{*}{ Production } & Problems with other parts of the business & 1 & \multirow{11}{*}{$\begin{array}{c}\text { Business } \\
\text { Management and } \\
\text { Financial Skills }\end{array}$} & Infrastructure bought on their own & 3 \\
\hline & Problems with filter availability (disk) & 1 & & Own investment in equipment & 3 \\
\hline & Problems in production process & 3 & & Employment of staff, salary & 1 \\
\hline & Reasons for stopping (production) & 3 & & Profitability & 1 \\
\hline & Help for maintenance of production & 1 & & Profitability challenges & 1 \\
\hline \multirow{7}{*}{$\begin{array}{c}\text { Collaboration and } \\
\text { Support }\end{array}$} & Form. relationships with other Org. & 1 & & Income through other products & 1 \\
\hline & Provider of production training & 1 & & Business management training & 2 \\
\hline & External help with setting up & 3 & & Bookkeeping & 2 \\
\hline & Support f. Mktg., Freq. of measures & 1 & & Planning of production & 1 \\
\hline & Sales channels & 1 & & Knowledge of costs & 2 \\
\hline & Funding of investment & 2 & & Different prices & 1 \\
\hline & Funding of production & 2 & \multirow{6}{*}{$\begin{array}{c}\text { Marketing Skills } \\
\text { and Effort }\end{array}$} & Marketing Training & 2 \\
\hline \multirow{4}{*}{$\begin{array}{l}\text { Availability of } \\
\text { Customers }\end{array}$} & Differences betw. income segments & 1 & & Knowledge about customers & 1 \\
\hline & Customer segments & 1 & & Sales channels & 1 \\
\hline & Population density & 2 & & Own Marketing Measures & 2 \\
\hline & Selling area & 2 & & Strategies for new customers & 2 \\
\hline \multirow{7}{*}{$\begin{array}{c}\text { External Influences } \\
\text { on Market (increasing } \\
\text { Demand) }\end{array}$} & Safety of water sources & 2 & & Effectiveness of own Marketing & 2 \\
\hline & Competition of other HWTS & 1 & \multirow{16}{*}{$\begin{array}{l}\text { Entrepreneurial } \\
\text { Spirit }\end{array}$} & Production of other products & 1 \\
\hline & Marketing Measures & 2 & & Percentage of income rel. to filters & 1 \\
\hline & Frequency of Marketing Measures & 2 & & Infrastructure bought on their own & 2 \\
\hline & Awareness Raising Activities & 1 & & Interest in training others & 1 \\
\hline & Recommendations of customers & 2 & & Own Marketing, strategy for new cust. & 2 \\
\hline & Effectiveness of Marketing & 3 & & Interest in continuation, Scale up & 3 \\
\hline \multirow{10}{*}{$\begin{array}{c}\text { Interest of } \\
\text { Customers in Filters }\end{array}$} & Problem of filter availability (demand) & 1 & & Organization, tidiness of site & 1 \\
\hline & Willingness to invest comp. to price & 1 & & Opn. on Trainings, impact of design & 1 \\
\hline & Percentage of people treating water & 3 & & Help with Setting up & 2 \\
\hline & Pot. customers (not yet treating) & 1 & & Quality Testing & 1 \\
\hline & HWTS Demand & 3 & & Knowledge spare parts, prod. time & 1 \\
\hline & Difficulty to find customers & 2 & & Problem solving methods & 2 \\
\hline & Satisfaction of customers & 1 & & Buying places, transport (special) & 1 \\
\hline & Complaints of customers & 1 & & After Sales Services & 2 \\
\hline & Reasons for not buying the Filter & 1 & & Help for maintenance of production & 1 \\
\hline & Reasons for stopping (demand) & 3 & & Innov. thinking, ind. spirit (observed) & 3 \\
\hline
\end{tabular}

Note: $\mathrm{W}=$ Weight of question within each condition.

\subsection{Developing the Scores}

Firstly, an evaluation was done of the answers given by the potters to the questions within the eight cases. Each condition was attributed a subjective rating of either "low" (1), "moderate" (2), "medium" (3), "high" (4), or "very high" (5) according to their answers and the impressions gained during the interview and the site inspection.

The scoring was repeated using a more methodical approach in a second step. Each question was given a weight between 1 for the least important question and 3 for the most important. A higher weight was given to the questions considered to have a greater influence than the other questions within each condition. For example, within the condition "Business Management and Financial Skills", 
we compared the questions: "Own investment in equipment", "Business management training" and "Different prices". The application of "Different prices" is a small aspect in the overall business managed by the potter and, therefore, received the lowest weight. Attending "Business management training", however, could have a large effect on the potter's entire business and was given more weight than "Different prices". The question regarding his "Own investment in equipment" was rated with the highest weight because it shows that the potter understands the business concept, is able and willing to invest and knows that without investing, important pieces of equipment might be missing, making production impossible.

The answer of the potter was then assessed as either positive $(+1)$, without influence $(0)$ or negative $(-1)$ for the filter business. Doing this ensured that when two potters gave the same or a similar answer to a question, it was evaluated in the same way and that all answers were taken into account. To summarize all the answers of a condition into one number, a weighted average was taken from all the questions within the condition. This resulted in a normalized score for each condition that ranged from -1 to 1 , which is used in further steps of the QCA.

\subsection{Comparing the Two Approaches}

Before continuing with the QCA a comparison was done between the two different scoring approaches. The score from the methodical approach was transformed into the same values used for the subjective scoring (1-5) by dividing the distance into five equal spaces: -1 to $-0.6=1 ;-0.599$ to $-0.2=2 ; 0.199$ to $-0.199=3 ; 0.2$ to $0.599=4$ and 0.6 to $1=5$.

The values between 1 and 5 obtained for each condition through the subjective and the methodological approaches were compared, by checking if the potters had received the same value in both of them. Within the $8 \times 8$ conditions, the values obtained through the different approaches were identical in 45 conditions and differed by 1 unit in 19 conditions.

The potters were ranked in three different ways. The first was by the number of filters sold. The potter with the highest number was assigned to rank 1 . The second and third ways were derived from the two scoring methods by summing up the values they received in the different conditions.

\subsection{QCA Procedure}

The scores ( -1 to 1$)$ reached via the methodical procedure were used to derive fuzzy-set scores for the QCA. In fuzzy-set scores a value close to 0 means that the condition is absent, while close to 1 means that the condition is present [25]. A linear equation was, therefore, calculated to change the range of values between -1 and 1 to the range between 0 and 1 .

The number of conditions to be included in the QCA had to be reduced as a high number of conditions is dysfunctional for a QCA [27]. The conditions addressed during the interview therefore were summarized into the four combined conditions: "Production" (R); "Collaboration and Support" (C); "Market" (M), which consists of the three sub-conditions influencing demand: "Availability of Customers", "External Influences on the Market" and "Interest of Customers in CS-Filters"; and "Potter" (P), consisting of three sub-conditions: "Business Management and Financial Skills", "Marketing Skills and Effort" and "Entrepreneurial Spirit". The sub-conditions were joined using logical OR, which means that the highest of the sub-conditions' scores became the score of the 
combined condition [28]. This procedure was adopted because either one of the sub-conditions could lead to sufficient demand or a successful potter, respectively. For the QCA, this means, that the condition "Market" is present (receiving a value close to 1) when one of its three sub-conditions received a high score.

Four conditions result in 16 different causal combinations as each condition can be either present or absent. The membership scores of the cases in each of these combinations were calculated using logical AND (represented in Table 2 with the asterisk *). This procedure chooses the smallest score among the conditions in the causal combination to be the membership score [28].

The outcome was defined as the successful continuation of the ceramic filter production. The scores for continuation were calculated using the number of filters sold by each site divided by 1000 . Sites with more than 1000 filters sold received an outcome score of 1 . This was done in order to reach a score of 0.5 for the one potter who was only producing filters from time to time, half in and half out of production. The scores for the termination of the business are the negation of those for continuation, the difference between the scores for continuation and 1 [28].

The consistency values of sufficient conditions for both the outcomes of continuation and termination are reported. They were calculated using the formulas described in Ragin (2006). The cut-off value was set to 0.75 [25,27]. Coverage values were also calculated according to Ragin (2006), as were consistency and coverage values for necessary conditions, but they are not displayed [25].

Table 2. Membership scores of all sites (roman numerals) in the causal combinations with at least one case with a membership score above 0.5 .

\begin{tabular}{|c|c|c|c|c|c|c|c|c|}
\hline \multirow{2}{*}{ Sites } & \multicolumn{2}{|c|}{ Outcome Scores } & \multicolumn{6}{|c|}{ Causal Combinations } \\
\hline & Cont. & Term. & $\mathbf{R} * \mathbf{C} * \sim \mathbf{M} * \mathbf{P}$ & $\mathbf{R} * \mathbf{C} * \sim \mathbf{M} * \mathbf{P}$ & $\sim \mathbf{R} * \sim \mathbf{C} * \mathbf{M} * \mathbf{P}$ & $\mathbf{R} * \mathbf{C} * \mathbf{M} * \mathbf{P}$ & $\mathbf{R} * \sim \mathbf{C} * \mathbf{M} * \mathbf{P}$ & $\mathbf{R} * \mathbf{C} * \mathbf{M} * \mathbf{P}$ \\
\hline I & 1 & 0 & 0.148 & 0.294 & 0.222 & 0.148 & 0.706 & 0.273 \\
\hline II & 1 & 0 & 0.235 & 0.235 & 0.222 & 0.550 & 0.273 & 0.450 \\
\hline III & 1 & 0 & 0.088 & 0.088 & 0.091 & 0.370 & 0.091 & 0.630 \\
\hline IV & 0.5 & 0.5 & 0.417 & 0.182 & 0.182 & 0.556 & 0.182 & 0.421 \\
\hline $\mathrm{V}$ & 0.175 & 0.825 & 0.050 & 0.083 & 0.545 & 0.050 & 0.167 & 0.167 \\
\hline VI & 0.15 & 0.85 & 0.083 & 0.083 & 0.545 & 0.167 & 0.167 & 0.167 \\
\hline VII & 0.15 & 0.85 & 0.556 & 0.211 & 0.211 & 0.269 & 0.211 & 0.211 \\
\hline VIII & 0.01 & 0.99 & 0.318 & 0.519 & 0.056 & 0.269 & 0.269 & 0.269 \\
\hline \multicolumn{2}{|c|}{ Consistency for } & Cont. & 0.623 & 0.664 & 0.580 & 0.811 & 0.837 & 0.870 \\
\hline \multicolumn{2}{|c|}{ Sufficiency } & Term. & 0.751 & 0.636 & 0.742 & 0.528 & 0.482 & 0.477 \\
\hline
\end{tabular}

Notes: $\mathrm{R}=$ "Production", $\mathrm{C}=$ "Collaboration", $\mathrm{M}=$ "Market", $\mathrm{P}=$ "Potter", * = Logical AND, $\sim$ Negation. Cont. $=$ Continuation, Term. $=$ Termination.

\section{Results and Discussion}

\subsection{The Potters' Stories}

Out of the 14 production sites that were visited, only four are still regularly producing filters, while another one produces only whenever stock runs out. Four began producing, but discontinued, and five entrepreneurs never managed to start production. One of the successfully operating sites, not included in this analysis, is the site of Hari Govinda Prajapati, who is the Nepal Field Director of Village Forward. In this position, he trains the potters and produces the disks required for his business and 
their businesses. He therefore plays a major role in the CS-filter business of Nepal. The potter who only sporadically produces, complained about the low availability of filter disks. He said that he would be willing to conduct marketing measures to increase demand in his area, but only if he were sure that he could buy a sufficient number of disks necessary to produce an increasing number of filters.

As outlined before, three different organizations provided the training for the potters and supported the set-up of their ceramic filter production. Even though they all worked together with Village Forward and with its Field Director Hari Govinda and have local staff, there were big differences in the results of their projects. The most successful outcome was achieved by Village Forward. Four potters supported by this organization are still producing filters. Only one interviewed potter supported by Village Forward no longer produces filters. HELVETAS supported the training and business set-up of two potters in the same area. Although they seem to have had favourable conditions for production and marketing, they gave up their production because of the high breakage of filters during firing (due to the utilization of inadequate clay). Although they tried different approaches to solve this problem, they have not yet managed to do so. The SanMark Initiative supported ten potters, out of whom seven were interviewed and all were found to no longer produce filters or to not even have started.

The two potters from HELVETAS were not the only potters who encountered a problem with clay. In two other cases after using inadequate clay, a different clay source was found. In a third case, the potter never started production due to financial reasons. The potters assisted by the SanMark Initiative received less support for starting up their production. They had to invest their own resources to pay some of the costs of their own furnaces and they had to make sure that they received the temperature measurement device necessary to control the firing of the filters. These barriers caused some of them to fail to set-up their own site. One potter refused the partial investment for the furnace granted by the supporting organization because it was less than the amount that was initially announced. As a result, he did not build his furnace. Two potters failed to build their furnaces even though they had received training on how to do it. Additionally, although the organizations said they would provide the temperature measurement device, two potters never received it. These two also did not manage to receive one on their own and, therefore, cannot produce at present even though they have a working kiln and all the other necessary equipment.

The lack of demand for the ceramic filter was a critical hurdle for two other potters that led to the termination of their production. They still had filters in stock and could have produced more, but were unable to sell them. These potters also stated that they were not willing and/or not able to create demand by conducting their own marketing measures and to build up their own distribution channels without external support. Part of the SanMark Initiative was to build up a distribution system with an outlet and sales people. According to the people interviewed from IDE Nepal and SAPPROS Nepal, this distribution network was never tested because the potters did not manage to start the production of filters during the project period. Unfortunately, the potters were also not informed that this assistance would be available from the SanMark Initiative, and did not have a chance to use this.

\subsection{Results of the Two Scoring Approaches}

In Table 3 the resulting values of the two different scoring approaches are summarized. For each condition and each production site (roman numerals), the values of both methods are given. Their total 
score and resulting ranking is listed for each site. As Table 3 displays, the ranking of the potters according to their total scores does not correspond with the number of filters sold. This might be due to the fact that even though a potter has received high scores for most conditions, a problem within an essential condition, such as lacking access to the resources required for production, can lead to the early termination of production (and thereby limit the total number of filters produced).

Table 3. Resulting values of the two scoring approaches for all sites (roman numerals) in the different conditions.

\begin{tabular}{|c|c|c|c|c|c|c|c|c|c|}
\hline \multirow{2}{*}{ Conditions } & \multirow{2}{*}{$\begin{array}{l}\text { Scoring } \\
\text { Method }\end{array}$} & \multicolumn{8}{|c|}{ Sites } \\
\hline & & $\mathbf{I}$ & II & III & IV & $\mathbf{V}$ & VI & VII & VIII \\
\hline \multirow{2}{*}{ Production (R) } & Subjective & 4 & 4 & 5 & 3 & 2 & 2 & 3 & 5 \\
\hline & Methodical & 4 & 4 & 5 & 3 & 1 & 1 & 3 & 5 \\
\hline \multirow{2}{*}{ Collaboration and Support (C) } & Subjective & 2 & 4 & 5 & 5 & 3 & 3 & 4 & 1 \\
\hline & Methodical & 2 & 4 & 5 & 5 & 3 & 3 & 4 & 2 \\
\hline \multirow{2}{*}{ Availability of Customers } & Subjective & 4 & 2 & 5 & 3 & 5 & 5 & 1 & 2 \\
\hline & Methodical & 4 & 3 & 4 & 3 & 5 & 5 & 1 & 2 \\
\hline \multirow{2}{*}{$\begin{array}{l}\text { External Influences on Market } \\
\text { (increasing demand) }\end{array}$} & Subjective & 4 & 4 & 3 & 2 & 5 & 5 & 1 & 1 \\
\hline & Methodical & 4 & 4 & 3 & 3 & 5 & 5 & 2 & 2 \\
\hline \multirow{2}{*}{ Interest in Filter } & Subjective & 4 & 4 & 5 & 2 & 5 & 5 & 1 & 2 \\
\hline & Methodical & 4 & 4 & 5 & 3 & 4 & 4 & 1 & 1 \\
\hline \multirow{2}{*}{$\begin{array}{c}\text { Business Management and } \\
\text { Financial Skills }\end{array}$} & Subjective & 5 & 2 & 3 & 3 & 5 & 3 & 1 & 3 \\
\hline & Methodical & 4 & 2 & 3 & 3 & 4 & 3 & 2 & 3 \\
\hline \multirow{2}{*}{ Marketing Skills and Effort } & Subjective & 3 & 3 & 2 & 2 & 5 & 4 & 1 & 2 \\
\hline & Methodical & 2 & 3 & 1 & 2 & 5 & 4 & 1 & 2 \\
\hline \multirow{2}{*}{ Entrepreneurial Spirit } & Subjective & 5 & 2 & 3 & 2 & 4 & 3 & 1 & 2 \\
\hline & Methodical & 5 & 2 & 4 & 2 & 3 & 3 & 1 & 3 \\
\hline \multirow{2}{*}{$\begin{array}{l}\text { Total Scores and Ranking } \\
\text { (Score: Rank) }\end{array}$} & Subjective ${ }^{1}$ & $31: 2$ & $25: 5$ & $31: 2$ & $22: 6$ & 34: 1 & $30: 4$ & $13: 8$ & 18: 7 \\
\hline & Methodical $^{2}$ & $29: 3$ & $26: 5$ & $30: 1$ & $24: 6$ & $30: 1$ & $28: 4$ & $15: 8$ & 20: 7 \\
\hline Total number of Filters sold & - & 15,000 & 4000 & 3750 & 500 & 175 & 150 & 150 & 10 \\
\hline
\end{tabular}

Notes: ${ }^{1}$ the total score (first number) and ranking (second number) reached through the subjective scoring;

2 the total score (first number) and ranking (second number) reached through the methodological scoring.

For two potters, the subjective and methodological scoring lead to differing scores in four conditions. One of them had made a rather positive impression during the interview while the other one gave the impression that he was unwilling to put more effort into the business. The first one was evaluated higher by the subjective method in all four conditions and the second one was evaluated lower in three of the four conditions. This demonstrates the importance of a scoring that is less influenced by the overall impression of the interviewer. This observation can also be extended to the other cases.

\subsection{Results of the $Q C A$}

Table 4 shows the fuzzy-set scores of the eight cases (roman numerals) that successfully established filter production for the conditions "Production" (R), "Collaboration and Support" (C), "Market" (M) and "Potter" (P).

Table 2 shows the membership scores of each site for the causal combinations of the four conditions "Production" (R), "Collaboration" (C), "Market" (M) and "Potter" (P) that had at least one case with a 
membership score of 0.5 or higher (underlined). A membership score of 0.5 or above shows that this case represents this causal combination better than the other cases. The asterisk * represents the combination with logical AND and the tilde $\sim$ represents the negation, meaning that the condition is not present, or low [28]. The outcome scores for continuation (Cont.) and termination (Term.) are also displayed in Table 2, as well as the consistency values for both outcomes.

Table 4. Fuzzy-set scores for each site of four combined conditions and six sub-conditions.

\begin{tabular}{ccccccccc}
\hline \multirow{2}{*}{ Conditions } & \multicolumn{1}{c}{ Sites } \\
\cline { 2 - 9 } & I & II & III & IV & V & VI & VII & VIII \\
\hline Production (R) & 0.778 & 0.778 & 0.889 & 0.556 & 0.167 & 0.167 & 0.556 & 0.944 \\
Collaboration and Support (C) & 0.273 & 0.727 & 0.909 & 0.818 & 0.455 & 0.455 & 0.727 & 0.318 \\
Market (M) joined by logical OR & 0.706 & 0.765 & 0.912 & 0.583 & 0.917 & 0.917 & 0.269 & 0.269 \\
Availability of Customers & 0.667 & 0.417 & 0.750 & 0.583 & 0.917 & 0.917 & 0.167 & 0.250 \\
Ext. Influences Market & 0.615 & 0.615 & 0.462 & 0.462 & 0.846 & 0.808 & 0.269 & 0.269 \\
Interest in Filter & 0.706 & 0.765 & 0.912 & 0.412 & 0.706 & 0.706 & 0.118 & 0.147 \\
Potter (P) joined by logical OR & 0.852 & 0.450 & 0.630 & 0.421 & 0.950 & 0.650 & 0.211 & 0.519 \\
Business Mgmt and Financial Skills & 0.816 & 0.237 & 0.421 & 0.421 & 0.737 & 0.421 & 0.211 & 0.500 \\
Marketing and Effort & 0.400 & 0.450 & 0.200 & 0.250 & 0.950 & 0.650 & 0.150 & 0.400 \\
Entrepreneurial Spirit & 0.852 & 0.389 & 0.630 & 0.370 & 0.593 & 0.556 & 0.185 & 0.519 \\
\hline
\end{tabular}

Looking at the combinations of conditions (= paths) that included the cases with a successful outcome (= filter production above 1000 pieces), the path to the outcome of "continuation of the production" can be described as $\mathrm{R}^{*} \mathrm{M}$. This path shows that smooth production and high demand for ceramic filters in the market lead to the sustainable operation of ceramic filter businesses. It was reached using Boolean logic to eliminate conditions. One of the successful potters has both high values within the condition "Collaboration" and high skills within the condition "Potter" in addition to high values for "Production" and "Marketing", while the other two have high values either in "Collaboration" or in "Potter". This shows that both trouble-free production and a big market are needed, and that strong collaboration and the high skills of the potter can replace each other. This path has an overall consistency of 0.88 and coverage of 0.84 ; the cases are highly consistent with the path and the path accounts for most of the successful production sites. One of the columns is slightly contradictory, with high membership of both potters number II and IV, as potter IV received the ambiguous outcome score of 0.5 . However, since he is still producing, the column should be taken into account.

There is only one causal combination with a consistency value above the cut-off, leading to the outcome of termination: $\mathrm{R}^{*} \mathrm{C}^{*} \sim \mathrm{M}^{*} \sim \mathrm{P}$, with a consistency value of 0.75 and a coverage value of 0.36 . This explains roughly one third of the failures. This path shows that even though production is problem free and collaboration is strong, a missing market and lack of skills on the part of the potter can lead to the termination of production. The other two columns containing cases with high membership in the outcome of termination show that collaboration can again be exchanged with the high skills of the potter and that there is an entirely different path where production problems are decisive.

Regarding the causes for the failure of the production sites, the QCA does not lead to completely new findings, but summarizes earlier observations and provides reasoning for them through the path of causal combinations it reveals. The QCA shows, however, which conditions are necessary for the successful continuation of a ceramic filter business. This was not directly visible by just looking 
qualitatively at the data, and shows one of the strengths of this method. Each of the cases is different, as each potter has his own individual story. The QCA however, provides a framework to systematically compare the different cases. It reduces the complexity and generalizes to a certain extent, while still allowing for a combination of conditions to be necessary for a certain outcome [26]. This evaluation also demonstrates that QCA is a valuable method for the analysis of a small number of cases [17-19]. With only eight cases, a well-justified explanation for the continuation or termination of production was found. On the other hand, a limitation of the QCA method is that many decisions regarding the definition and evaluation of conditions have to be taken and are very dependent on the information available and the preferences of the author. However, the choice of variables and the translation of not directly quantifiable information into scores also need to be done when using other methods.

This study could have been more conclusive if it had included all the trained potters in Nepal. This would surely have led to making more information available and would have provided additional insights, as well as more comprehensive results and would have given the results more general significance. Future studies on this subject should expand the number of cases to be evaluated, and should include cases from other geographical contexts to provide ground for broader generalizations.

\subsection{Concerns and Recommendations}

Demand for the filters is critical for the successful establishment and long-term operation of production sites. According to the potters' answers, people in their areas are aware of the importance of drinking safe water, but a majority thinks that their water is safe. This leads to low demand for ceramic filters. To increase demand, comprehensive awareness raising campaigns and more social marketing activities would be necessary. Such campaigns require the implementation of systemic behavior change interventions over an extended period of time [29-31].

A surprising finding during the interviews was that people living in areas where the groundwater is contaminated by Arsenic were particularly interested in buying CS-filters. They intended to use the CS-filters to remove Arsenic from the water by putting nails or other iron parts and sand into the filter-holder above the disk. Even though these materials can potentially have the effect of adsorbing the Arsenic onto ferric hydroxides [32], such a practice does not produce reliable results.

The monopoly over the production of filter disks by one potter limits their availability and thereby presents an obstacle to the sustainable operation and scale-up of other production sites. Establishing a second filter disk producer would help to meet the demand and also support market growth.

Another critical issue to be addressed is the quality control of the filter disks. Several studies have investigated and demonstrated the microbiological effectiveness of different ceramic filters $[8,9,11,33]$. However, without quality control the microbiological safety of the water produced by using them cannot be guaranteed. The quality control measures implemented at the inspected sites lack systematic rigor, are not done regularly and should be significantly improved. External control visits should also take place.

\section{Conclusions}

The evaluation showed that smooth production including reliable access to all the resources required, as well as a good marketing context were essential for the successful operation of a ceramic filter business for the eight potters analyzed in this study. Inputs from and collaboration with other 
organizations can facilitate and strengthen "Production" and "Market", but are not required if "Production" and "Market" are already strong. However, when essential elements within these two conditions are lacking, this often leads to the termination of production.

The different outputs achieved by the three organizations training potters in how to establish their own ceramic filter businesses show that adequate initial technical support, as well as proper access to all the equipment and resources required for production, are essential to get production up and running. However, too many of the entrepreneurs trained in Nepal failed due to problems relating to starting and establishing filter production.

Furthermore, although several of the potters managed to successfully establish CS-filter production, they discontinued their businesses due to low product sales. This seems to relate to a weak focus on marketing during implementation. In the cases evaluated, comprehensive behaviour change and social marketing activities were only marginally implemented - Or had been stopped several months prior to the establishment of CS-filter production. This result supports findings from earlier studies that showed that entrepreneurs who are dedicated to establishing water treatment product businesses often face challenges in sustainably running their businesses due to low demand from households for safe water or water treatment products [34-36]. Support to establish local production of household water treatment products, therefore, should not be delinked from efforts to establish a conducive market environment.

\section{Acknowledgments}

The authors would like to extend thanks to Suman Shakya and Purnima Shakya of the ENPHO Office for their input and support during the planning of the study, Urmila Lama for conducting and translating the interviews, Chintu Thapa for the logistical support and the potters and organizations for their participating in the interviews. We would also like to thank the Solaqua Foundation for providing financial support.

\section{Author Contributions}

Regula Meierhofer designed the study and remotely supervised the data collection. Anne Bogler conducted the interviews in Nepal, analyzed the data and wrote the first draft of the manuscript, with input from Regula Meierhofer. Both authors reviewed the final manuscript.

\section{Conflicts of Interest}

The authors declare no conflict of interest.

\section{References}

1. World Health Organization (WHO). Investigating in Water and Sanitation: Increasing Access, Reducing Inequalities. Un-water Global Analysis and Assessment of Sanitation and Drinking Water; Glaas Report; WHO: Geneva, Switzerland, 2014.

2. Brown, J.; Clasen, T. High adherence is necessary to realize health gains from water quality interventions. PLoS ONE 2012, 7, doi:10.1371/journal.pone.0036735. 
3. U.S. Agency International Development (USAID). Bringing the Consumer to the Table: Perceptions and Practice of Household Water Treatment Methods in Nepal; Hygiene Improvement Project (HIP); Academy for Educational Development: Washington, DC, USA, 2006.

4. Clasen, T. Scaling up Household Water Treatment among Low-income Populations; World Health Organization: Geneva, Switzerland, 2009.

5. Rice, P.M. Pottery Analysis; University of Chicago Press: Chicago, IL, USA, 1987.

6. Cooper, E. Ten Thousand Years of Pottery; University of Pennsylvania Press: Philadelphia, PA, USA, 2000.

7. Hayes, J.W. Late Roman Pottery; British School at Rome: Rome, Italy, 1970; Volume 38.

8. Lantagne, D.; Klarman, M.; Mayer, A.; Preston, K.; Napotnik, J.; Jellison, K. Effect of production variables on microbiological removal in locally-produced ceramic filters for household water treatment. Int. J. Environ. Health Res. 2010, 20, 171-187.

9. Oyanedel-Craver, V.A.; Smith, J.A. Sustainable colloidal-silver-impregnated ceramic filter for point-of-use water treatment. Environ. Sci. Technol. 2008, 42, 927-933.

10. Ron Rivera. Available online: http://www.thelancet.com/pdfs/journals/lancet/PIIS0140-6736\%2808\% 2961859-0.pdf (accessed on 6 July 2015).

11. Brown, J.; Sobsey, M.D. Microbiological effectiveness of locally produced ceramic filters for drinking water treatment in cambodia. J. Water Health 2010, 8, 1-10.

12. VillageForward. Available online: http: //www.villageforward.com (accessed on 26 November 2014).

13. Anderson, J.; Billou, N. Serving the world's poor: Innovation at the base of the economic pyramid. J. Bus. Strategy 2007, 28, 14-21.

14. Osterwalder, A.; Pigneur, Y. Business Model Generation; John Wiley \& Sons: Hoboken, NJ, USA, 2010.

15. Standards of Good Practice in Qualitative Comparative Analysis (QCA) and Fuzzy-Sets. Available online: http://www.compasss.org/wpseries/WagemannSchneider2007.pdf (acessed on 6 July 2015).

16. Rihoux, B. Qualitative comparative analysis (QCA) and related systematic comparative methods: Recent advances and remaining challenges for social science research. Int. Soc. 2006, 21, 679-706.

17. Rihoux, B. Bridging the gap between the qualitative and quantitative worlds? A retrospective and prospective view on qualitative comparative analysis. Field Methods 2003, 15, 351-365.

18. Scouvart, M.; Adams, R.; Caldas, M.; Dale, V.; Mertens, B.; Nedelec, V.; Pacheco, P.; Rihoux, B.; Lambin, E.F. Causes of deforestation in the brazilian amazon: A qualitative comparative analysis. J. Land Use Sci. 2007, 2, 257-282.

19. Fischer, M. Institutions and coalitions in policy processes: A cross-sectoral comparison. J. Public Policy 2014, 35, 1-24, doi:10.1017/S0143814X14000166.

20. Kitchener, M.; Beynon, M.; Harrington, C. Qualitative comparative analysis and public services research: Lessons from an early application. Public Manag. Rev. 2002, 4, 485-504.

21. Vanderborght, Y.; Yamasaki, S. Des cas logiques contradictoires? Un piège de l'aqqc déjoué à travers l'étude de la faisabilité politique de l'allocation universelle. Rev. Int. Polit. Comp. 2004, 11, 51-66.

22. Brueggemann, J.; Boswell, T. Realizing solidarity: Sources of interracial unionism during the great depression. Work Occup. 1998, 25, 436-482. 
23. Hellström, E. Conflict Cultures: Qualitative Comparative Analysis of Environmental Conflicts in Forestry; The Finnish Society of Forest Science/The Finnish Forest Research Institute: Helsinki, Finland, 2001.

24. Ragin, C.C. The Comparative Method: Moving beyond Qualitative and Quantitative Strategies; University California Press: Berkeley, CA, USA, 1987.

25. Ragin, C.C. Set relations in social research: Evaluating their consistency and coverage. Polit. Anal. 2006, 14, 291-310.

26. Srinivasan, V.; Lambin, E.F.; Gorelick, S.M.; Thompson, B.H.; Rozelle, S. The nature and causes of the global water crisis: Syndromes from a meta-analysis of coupled human-water studies. Water Resour. Res. 2012, 48, doi:10.1029/2011WR011087.

27. Schneider, C.Q.; Wagemann, C. Standards of good practice in qualitative comparative analysis (QCA) and fuzzy-sets. Comp. Sociol. 2010, 9, 397-418.

28. Ragin, C.C. Qualitative comparative analysis using fuzzy sets (FSQCA). In Configurational Comparative Analysis; Rihoux, B., Ragin, C.C., Eds.; Sage Publications: Thousand Oaks, CA, USA, 2009.

29. Mosler, H.J. A systematic approach to behavior change interventions for the water and sanitation sector in developing countries: A conceptual model, a review, and a guideline. Int. J. Environ. Health Res. 2012, 22, 431-449.

30. Mosler, H.J.; Kraemer, S. Which psychological factors change when habitual water treatment practices alter? J. Public Health (Germany) 2012, 20, 71-79.

31. Evans, W.D.; Pattanayak, S.K.; Young, S.; Buszin, J.; Rai, S.; Bihm, J.W. Social marketing of water and sanitation products: A systematic review of peer-reviewed literature. Soc. Sci. Med. 2014, 110, 18-25.

32. Crittenden, J.C. Mwh's Water Treatment: Principles and Design; John Wiley \& Sons, Inc.: Hoboken, NJ, USA, 2012.

33. Kallman, E.N.; Oyanedel-Craver, V.A.; Smith, J.A. Ceramic filters impregnated with silver nanoparticles for point-of-use water treatment in rural guatemala. J. Environ. Eng. 2011, 137, 407-415.

34. Access to Safe Water for the Base of the Pyramid. Available online: http://hystra.com/safe-water (accessed on 2 July 2015).

35. PATH. Perspectives. Commercial Approaches to Delivering Household Water Treatment and Safe Storage Products and Solutions to Low-income Households; Program for Appropriate Technology in Health: Seattle, WA, USA, 2012.

36. Gero, A.; Carrard, N.; Murta, J.; Willetts, J. Private and social enterprise roles in water, sanitation and hygiene for the poor: A systematic review. J. Water Sanit. Hyg. for Dev. 2014, 4, 331-345.

(C) 2015 by the authors; licensee MDPI, Basel, Switzerland. This article is an open access article distributed under the terms and conditions of the Creative Commons Attribution license (http://creativecommons.org/licenses/by/4.0/). 